new country. The teachers themselves debated the adaptations that were required, and in one form or another that debate continues today in every developing country which has a medical school. The relative poverty of many developing countries adds further point to the questioning of how best its resources should be used in meeting the medical needs of the population.

Cuestions of this kind were prominent in the first International Congress on Basic Medical Sciences in Africa held at Lusaka, the capital of Zambia, on 7-14 March, organized by Professor G. C. Ezeitlo, head of the department of physiology at Lusaka. The conference was attended by representatives from 18 African countries and invited as its chief guest Professor D. H. Smyth, F.R.S., head of the department of physiology at Sheffield. One of the declared objects of the congress was to encourage basic research in medical schools in Africa so as to provide knowledge of the mechanisms underlying the diseases which are the major problems there and to discover more effective methods of investigating, treating, and preventing them. Appropriately, therefore, the conference attracted as representatives men and women who covered a wide variety of disciplines. Among them were clinicians, biochemists, pathologists in different branches of that complex specialty, anatomists, and parasitologists. As well as discussing some of the problems peculiar to the tropical environment in which they live and work-such as bilharzia, the carcinogenic effects of homebrewed alcohol, protein malnutrition, and the carriage of disease by arthropods-they took up the subject of normal values for various structural and functional data of the human body. The baselines on which chemical pathologists work are usually derived from Caucasian populations, and some of them may need to be modified if they are to suit African populations. Furthermore, it is worth remembering that Africa itself includes people of very disparate origins. Even in the centre of tropical Africa there are great variations between the exceptionally tall peoples, for instance, of the soutbern Sudan and the Pygmy peoples of the Ituri Forest. The investigation and redefinition of these baselines must rank as one of the first tasks for academic research in Africa.

The conference spent some time also discussing the sort of education that should be provided in the medical schools both for undergraduate students and for doctors in practice. The pressing needs of under-doctored populations in developing countries make the provision of staff, finance, and even time a matter of serious concern in many of their medical schools. In addition, these medical schools are acutely aware of what Professor 0 . O. Akinkugbe, of Ibadan, recently declared to be the most urgent and compelling one, namely, the relevance of their teaching. ${ }^{1}$ Medical schools in developed Western countries are themselves going through an experimental phase in an attempt to adapt their teaching more closely to the needs of the community. Very different programmes are on offer and their efficacy has yet to be compared. Much could, in fact, be learnt from the experience of developing countries in tackling these problems, and it is greatly to be hoped that British schools will learn from Africa's experiments as well as offering Africa the lessons of our own attempts to put scientific needs into a practical context.

In opening the conference the Zambian Minister of Health drew attention to some of these educational problems and they will no doubt recur in the second congress to be held at Khartoum next year, which coinoides with the jubilee of the founding of the Khartoum Medical School. Everyone concerned with the contribution which newer countries can make to the ideas governing medical education and research will welcome this African development and extend warmest wishes for its successful nature.

1 British Medical foumal, 1973, 1, 474.

\section{Complications of Vagotomy}

Complications may develop during or after any operation, and vagotomy is no exception. In one form or another it is now the commonest surgical treatment of duodenal ulcer. Over the years the technique and the type of vagotomy practised have been modified in order to minimize the ill effects. These may be immediate, intermediate, or late.

The immediate and intermediate complications associated with vagotomy have been highlighted by a recent study from the Massachusetts General Hospital. ${ }^{1}$ In a survey of 1,096 operations significant complications developed in $4.8 \%$ of patients.

One of the most serious operative accidents is perforation of the oesophagus during the search for the vagal fibres. This occurred in five cases. In three it was recognized immediately and repaired without incident, but in the other two it was not recognized in time and re-exploration was required. Both patients had a protracted postoperative course, and one died. Failure to recognize oesophageal perforation is likely to lead to death. ${ }^{2}$ Previous operations around the oesophageal hiatus obliterate the tissue planes and make oesophageal damage more likely.

Injury to the spleen, requiring splenectomy, was comparatively common and occurred in 30 patients $(2 \cdot 7 \%)$. Complications are specially common after inadvertent splenectomy and include venous thrombosis and subphrenic infection. Sometimes the latter may not declare itself for some months. ${ }^{3}$ Intraperitoneal haemorrhage requiring re-exploration occurred in three cases. Two of the patients died, but both had serious predisposing causes (von Willebrand's disease and portal hypertension). Occasionally damage to a major lymphatic trunk at the oesophageal hiatus results in chylous ascites. Reoperation and ligation of the trunk is necessary to control the ascites. ${ }^{4}$

In the early postoperative period dysphagia is occasionally troublesome. 56 In the present series it occurred in 12 patients $(1 \cdot 1 \%)$. In five it resolved spontaneously but the remainder required bouginage. In the majority dysphagia began within 1-2 months of operation, and only one patient required repeated bouginage; the remainder responded to one dilatation. The barium swallow in these cases may suggest achalasia, but at oesophagoscopy all had a definite organic stricture which required dilatation before the oesophagoscope would pass through it. The cause of the oesophageal obstruction has been variously ascribed to denervation, oesophagitis, and fibrosis in the oesophageal wall as a result of oesophageal mobilization. In one study of 100 patients undergoing selective vagotomy the incidence of dysphagia was $13 \%,{ }^{7}$ but in most other series it is about $2-4 \%$.

Interference with gastric emptying is a well-recognized effect of total denervation of the stomach, so that a drainage procedure has to be added. Though vagotomy can be shown to delay gastric emptying even in the presence of an adequate drainage operation, this is not usually significant clinically. ${ }^{8}$ 
Even if there has been pyloric obstruction before operation the return of gastric function is usually normal after vagotomy and drainage. Most of the delays in gastric emptying after vagotomy probably result from stromal dysfunction, for similar problems are sometimes seen after gastric resection without vagotomy. 9

The late complications following the various vagotomy operations result from (1) drainage operation, (2) denervation of other viscera, and (3) incomplete nerve section, which results in recurrent ulceration.

Any procedure for gastric drainage destroys or bypasses the normal mechanism controlling gastric emptying, and the "osmotic shield" function of the stomach is lost. The rapid transfer of hyperosmolar solutions into the small bowel results in dumping. Avoidance of the drainage procedure in the operation of highly selective vagotomy leads to a very low incidence of dumping. ${ }^{10}$

Denervation of the gall bladder causes demonstrable radiological change in gall bladder function, ${ }^{11}$ but as yet there is no clear evidence that this leads to an increase in formation of gall stones.

Post-vagotomy diarrhoea probably results from a combination of unregulated gastric emptying and denervation of the small bowel. It occurs in about $25 \%$ of patients after truncal vagotomy. For the majority the increased frequency of bowel action is an unexpected bonus of the operation. The incidence of severe and disabling diarrhoea is low, probably about $1 \%$. In a recent study the effect of ingesting $350 \mathrm{ml}$ of $25 \%$ glucose on an empty stomach was compared in three groups of patients. ${ }^{12}$ It resulted in diarrhoea in $67 \%$ of patients after truncal vagotomy with pyloroplasty, in $60 \%$ patients after truncal vagotomy with pyloroplasty, in $60 \%$ only $13 \%$ after highly selective vagotomy with no drainage procedure. These results suggest that uncontrolled gastric emptying may play a major part in the development of diarrhoea.

The long-term nutritional and metabolic disturbances after vagotomy and gastroenterostomy ${ }^{13}$ probably result from a combination of reduced acid secretion and uncontrolled gastric emptying.

Although incomplete nerve section is not a complication of the operation, it is a calamity for the patient who develops recurrent symptoms. Surgeons vary greatly in their ability to denervate the stomach, and success is not always related to experience. ${ }^{14}$ Incomplete nerve section would be avoided if a simple method existed for the recognition of a complete vagotomy. Though good results have been reported with the electrical stimulation test, ${ }^{15}$ this method has not been widely adopted.

Highly selective (proximal gastric vagotomy) seeks to avoid most of the late complications attributable to vagotomy. It is the logical development of vagal section, for it denervates only the secretory cell mass, leaving the gastric antrum, pylorus, and duodenum intact. It obviates the need for a drainage procedure. The early results are encouraging in the main, but really long-term follow-up results are required before a full and objective assessment can be made of its place in the surgery of duodenal ulcer.

Wirthlin, L. S., and Malt, R. A., Surgery, Gynecology and Obstetrics, 1972, 135, 913.

2 Price, J. J., Powis, J. A., and Morrissey, D. M., British fournal of Surgery, $1972,59,936$

Rosenberg, M., Lancet, 1968, 2, 379.

- Musgrove, J. E., Annals of Surgery, 1972, 175, 67

Guillory, J. R., and Clagett, O. T., Surgical Clinics of North America, $1967,47,833$.

- Edwards, D. A. W., Lancet, 1970, 2, 90.
' Ruckley, C. V., Falconer, C. W. A., Small, W. P., and Smith, A. N., British fournal of Surgery, 1970, 57, 245.

Buckler, K. G., Gut, 1967, 8, 137.

- Mathieson, A. J. M., British Yournal of Surgery, 1965, 52, 657.

${ }^{1}$ Humphrey, C. S., Johnston, D., Walker, B. E., Pulvertaft, C. N., and Goligher, J. C., British Medical fournal, 1972, 3, 785 .

11 Tinker, J., Lawson, T. R., and Cox, A. G., Gut, 1968, 9, 733 12 Johnston, D., Humphrey, C. S., Walker, B. E., Pulvertaft, C. N., and 18 Wheldon, E. J., Venables, C. W., and Johnston, I. D. A., Lancet, 1970, 1,

14 Johnston, D., and Goligher, J. C., Gut, 1971, 12, 963.

15 Burge, H., and Vane, J. R., British Medical fournal, 1958, 1, 615.

\section{A Marker for Medullary Carcinoma of Thyroid}

Medullary carcinoma of the thyroid is a tumour of the parafollicular or $\mathrm{C}$ cells, which normally produce calcitonin. ${ }^{1}$ Tumour cells continue to synthesize and secrete large amounts of calcitonin, and detection of increased amounts of this hormone in the circulation has provided a biochemical marker for the disease. A number of other humoral agents may be secreted by the medullary carcinoma, including 5-hydroxytryptamine, corticotrophin, ${ }^{2}$ prostaglandins, ${ }^{3}$ and histaminase. ${ }^{4-6}$

Histaminase is an enzyme that catalyses the deamination of histamine in tissues. High enzyme activity is found normally only in human intestine, kidney, and placenta, and levels of the enzyme in the serum increase during pregnancy and after injection of heparin. High tissue histaminase activity is found consistently in medullary carcinoma of the thyroid and its metastases, but not in other tumours, 56 and it appears to be a specific marker for medullary carcinoma of the thyroid. In 59 patients with a variety of other diseases and neoplasms a raised serum concentration of histaminase was found only once-in a woman with metastatic adenocarcinoma of the breast. ${ }^{5}$ But serum histaminase levels are not always raised in patients with medullary carcinoma of the thyroid. Raised values were found in 21 out of 42 affected patients, including 14 from families with inherited medullary carcinoma and seven with sporadic disease. ${ }^{5}$ Patients with metastatic disease tend to have higher values than those with localized disease; 18 out of 26 patients with metastatic disease had raised levels, whereas in only 3 out of 16 of those with localized disease were serum histaminase levels high.5 The highest serum histaminase levels are seen in patients with pulmonary metastases.

What then is the place of histaminase activity measurements in the diagnosis and management of patients with medullary carcinoma of the thyroid? The finding of high basal calcitonin levels and an exaggerated calcitonin response to calcium infusion remains the best method of separating patients with early medullary carcinoma of the thyroid from normal persons.7 Raised serum histaminase activity provides further support for the presence of a medullary carcinoma of the thyroid and is evidence of extrathyroidal disease. After removal of the primary tumour, high serum histaminase activity suggests that residual tumour is present, even if the basal calcitonin has returned to normal. Measurements of histaminase activity in tissues removed from patients suspected of medullary carcinoma of the thyroid can complement microscopical examination of these tissues. ${ }^{6}$

Measuring the serum histaminase activity in cases of suspected medullary carcinoma of the thyroid is a further 